\title{
ASML EUV Pioneers Photo Montage
}

, "ASML EUV Pioneers Photo Montage," Proc. SPIE 11323, Extreme Ultraviolet (EUV) Lithography XI, 113232Q (30 July 2020); doi: $10.1117 / 12.2580464$

SPIE. Event: SPIE Advanced Lithography, 2020, San Jose, California, United States 

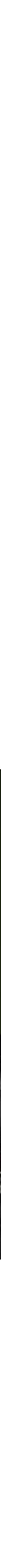

Proc. of SPIE Vol. $11323113232 \mathrm{Q}-3$ 

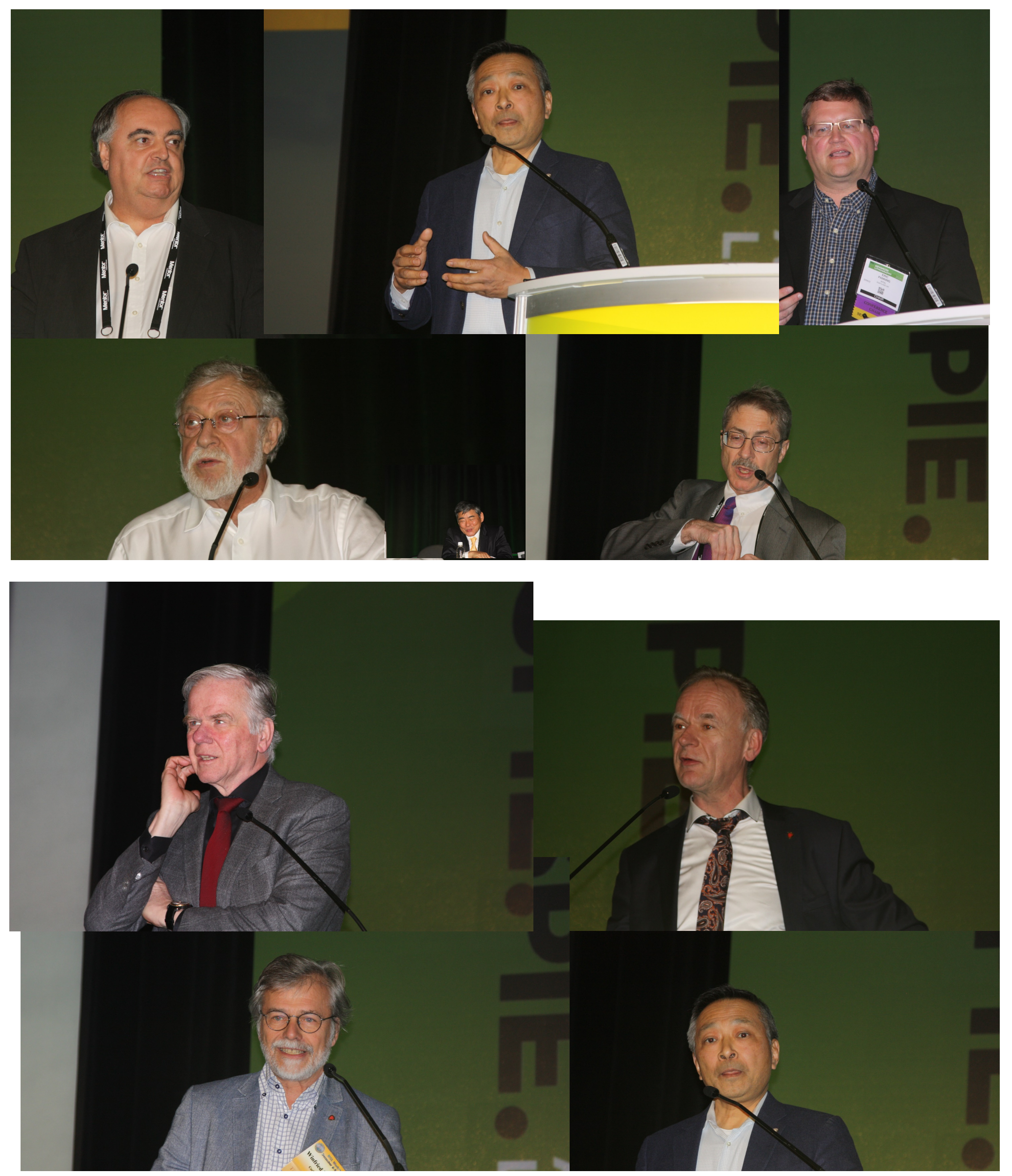

Proc. of SPIE Vol. $11323113232 \mathrm{Q}-4$

Downloaded From: https://www.spiedigitallibrary.org/conference-proceedings-of-spie on 26 Apr 2023 Terms of Use: https://www.spiedigitallibrary.org/terms-of-use 

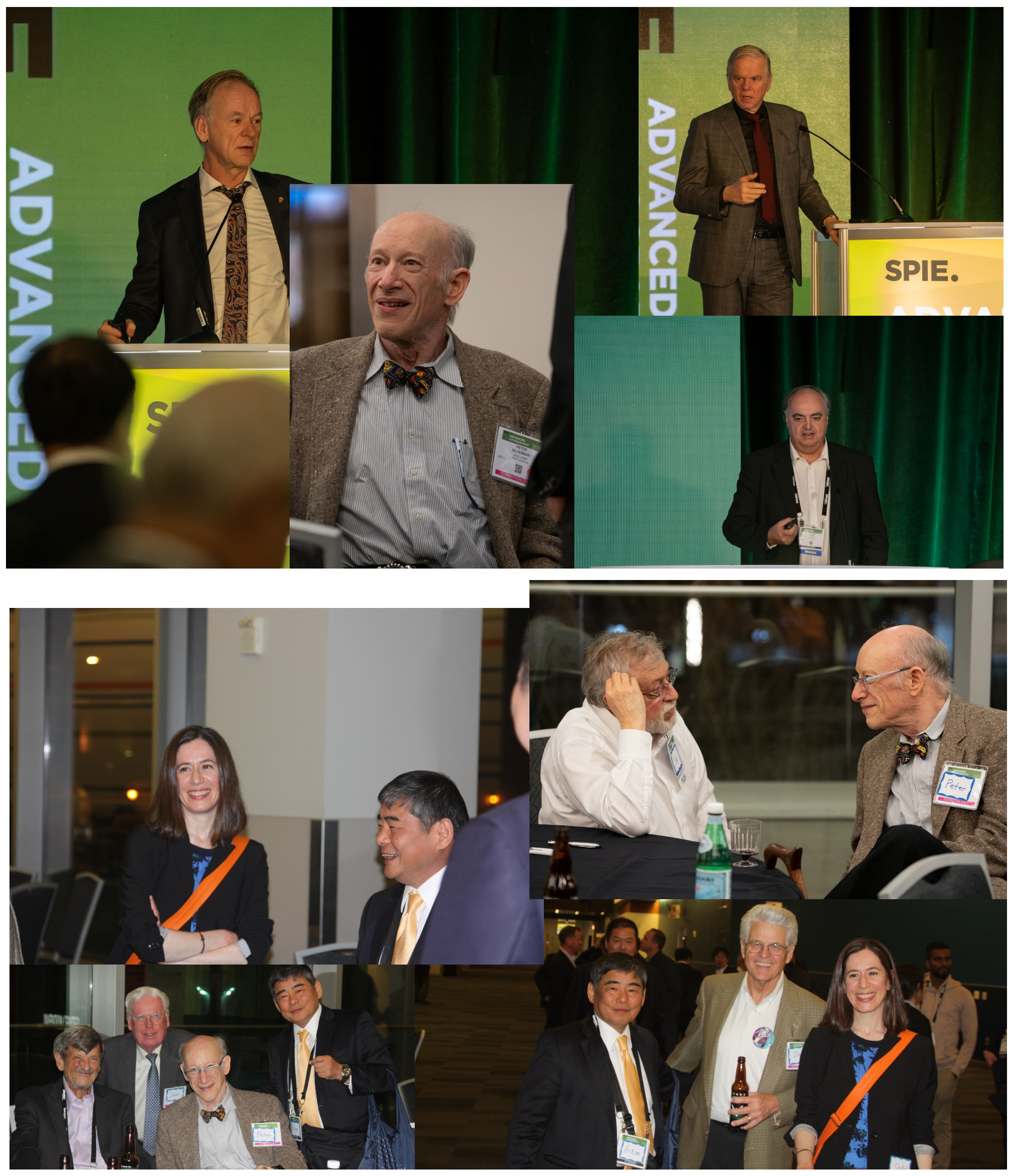

Proc. of SPIE Vol. $11323113232 \mathrm{Q}-5$ 